\title{
HUBUNGAN MASA KERJA DENGAN KEJADIAN CTS PADA PEKERJA PEMETIK DAUN TEH
}

\author{
Moch. Bahrudin ${ }^{1}$, Resi Lystianto Putra Perdana ${ }^{2}$, Hafif Fitra Alief Sultana ${ }^{3}$ \\ Fakultas Kedokteran, Universitas Muhammadiyah Malang, J1. Bendungan Sutami 188 A Sumbersari malang, \\ Lowokwaru, Kota Malang, 65145, Indonesia, (0341) 582060
}

\begin{abstract}
ABSTRAK
Latar belakang: CTS merupakan penyakit yang sering dijumpai pada pekerja industri dalam setiap kasus penyakit akibat kerja di beberapa negara. Terdapat beberapa faktor yang dapat mempengaruhi angka kejadian CTS, salah satunya yaitu masa kerja. Tujuan penelitian: Mengetahui hubungan masa kerja terhadap kejadian CTS pada pekerja pemetik daun teh. Metode penelitian: Analitik observasional dengan pendekatan Cross Sectional. Teknik pengambilan sampel menggunakan metode consecutive sampling dan didapatkan sampel sebanyak 85 pekerja. Hasil penelitian dan Diskusi: Angka kejadian CTS pada pekerja pemetik daun teh adalah 56 (65,9\%), kejadian CTS meningkat setelah umur 40 tahun dan kejadian CTS tertinggi pada umur 50-59 tahun (30,6\%), kejadian CTS meningkat setelah masa kerja 30 tahun dan kejadian CTS tertinggi terjadi pada masa kerja 30-39 tahun (31,8\%). Korelasi antara masa kerja dengan kejadian CTS menunjukan nilai korelasi positif $(0,263)$ dengan nilai signifikansi $0,015(<0,05)$, yang artinya semakin lama masa kerja maka angka kejadian CTS semakin besar. Kesimpulan: Semakin lama masa kerja semakin tinggi resiko terjadinya CTS
\end{abstract}

Kata kunci: Masa kerja, pekerja pemetik daun teh, CTS.

\section{ABSTRACT}

Background: CTS is considered to be the most common disease among industrial workers and found in every single case of occupational disease in some countries. There are some factors that can affect the prevalence of CTS, one of them is the working period. Objectives: To determine the relationship between working period and prevalence of CTS among among tea leaf pickers workers. Method: This was an analytic observational research with cross sectional approach. Consecutive sampling method was used to get samples with the sample size of 85 workers. Result and Discussion: The incidence of CTS in tea leaf pickers workers was 56 (65.9\%), CTS incidence increases after age 40 years and the highest incidence of CTS at the age of 50-59 years (30.6\%), the incidence of CTS increased after working 30 years and CTS incidence was highest in the 30-39-year tenure (31.8\%). The correlation between working periods with the incidence of CTS showed the value of a positive correlation (0.263) with a significance value of $0.015(<0.05)$; which means that the longer the tenure, the greater the incidence of CTS. Conclusion: The longer of working periods, the higher the risk of CTS in Tea Leaf Pickers Workers

Key words: Working period, Tea Leaf Pickers Workers, CTS

\section{Pendahuluan}

CTS adalah sindroma yang timbul akibat Nervus medianus tertekan di dalam terowongan karpal (Carpal Tunnel) di pergelangan tangan, sewaktu nervus melewati terowongan tersebut dari lengan bawah ke tangan (Atya dan Mansour, 2011, Bahrudin,2013).

Carpal tunnel syndrome (CTS) merupakan salah satu penyakit yang dilaporkan oleh badan-badan statistik perburuhan di negara maju sebagai penyakit yang sering dijumpai di kalangan pekerja-pekerja industri (Bugajska et al, 2007). Laporan International Labour Organization (ILO) menunjukkan bahwa CTS hampir selalu ditemukan dalam setiap kasus penyakit akibat kerja di beberapa negara. Bahkan di negara Cina pada tahun 2010 terjadi peningkatan jumlah kasus CTS akibat kerja sebesar kurang lebih 30\% dibandingkan tahun 2001. (ILO, 2013). Tingginya angka prevalensi yang diikuti dengan tingginya biaya yang harus dikeluarkan (pengobatan medis, rehabilitasi, kompensasi hilangnya jam kerja, biaya pensiun awal, juga pelatihan pekerja baru, dan lain-lain) membuat permasalahan ini menjadi masalah besar dalam dunia okupasi (Kurniawan et al., 2008).

Perkembangan dunia kerja yang semakin komplek disertai dengan era globalisasi menjadikan persaingan semakin ketat dalam segala sektor. Hal ini menjadi tuntutan yang tidak dapat dielakkan lagi. Mengingat Indonesia adalah negara agraris maka sektor pertanian sangatlah berperan dalam menunjang perekonomian negara. Untuk itu Indonesia harus meningkatkan kuantitas dan kualitas hasil pertaniannya. (Budiman, 2013)

Salah satu sektor pertanian yang berperan penting dalam menambah devisa negara adalah perkebunan teh. Pada tahun 2008 tercatat nilai ekspor teh olahan Indonesia mencapai US \$162,8 juta, tahun 2009 sebesar US \$174,4 juta, dan tahun 2010 mencapai US \$ 184,9 juta atau meningkat 6\% dari tahun 2009. (Kementrian Pertanian, 2014)

Kondisi dan perkembangan agroindustri teh di Indonesia sendiri dalam periode 2007-2010 mengalami 
peningkatan, baik jumlah perusahaan, produksi, maupun investasi serta tenaga kerja yang diserap. Berdasarkan data Kementrian Pertanian pada tahun 2009, total luas perkebunan teh yang ada di Indonesia adalah 126.251 Ha, yang tersebar di berbagai provinsi di Indonesia. Provinsi yang memiliki perkebunan teh terluas adalah Jawa Barat, yaitu seluas 97. $138 \mathrm{Ha}$ yang tersebar di berbagai daerah di Jawa Barat atau sebanyak $77 \%$ dari total luas perkebunan teh yang ada di Indonesia. Sedangkan di Kabupaten Malang terdapat perkebunan teh seluas 629 Ha yang terletak di desa Toyomarto Kecamatan Singosari dan Desa Wonorejo Kecamatan Lawang yang dinamakan Kebun Teh Wonosari. Hal ini membuat sebagian penduduk desa tersebut bekerja sebagai pemetik daun teh. (Kementrian Pertanian 2014; Pemerintah Kabupaten Malang 2015)

Masa kerja menunjukkan lamanya paparan di tempat kerja. Sehingga, semakin lama masa kerja maka akan semakin tinggi resiko terjadinya penyakit akibat kerja, salah satunya adalah CTS. Salah satu usaha industri yang berpotensi menimbulkan penyakit CTS adalah perkebunan teh.

Dari latar belakang tersebut peneliti tertarik untuk meneliti tentang hubungan masa kerja terhadap kejadian CTS pada pekerja perkebunan teh dan membuktikan apakah terdapat hubungan masa kerja terhadap kejadian CTS pada pekerja pemetik daun teh.

\section{Metode Penelitian}

Jenis penelitian yang digunakan adalah analitik observasional dengan pendekatan secara cross sectional. Penelitian akan dilakukan di Kebun Teh Wonosari, desa Toyomarto, Kecamatan Singosari, Kabupaten Malang kurang lebih 1bulan bulan Juli sampai dengan bulan Agustus 2016

Populasi pada penelitian ini adalah pemetik daun teh di Kabupaten Malang. Sampelnya adalah pemetik daun teh di Kebun Teh Wonosari, desa Toyomarto, Kecamatan Singosari, Kabupaten Malang yang memenuhi kriteria inklusi dan eksklusi. Teknik pengambilan sampel menggunakan Consecutive sampling dengan kriteria inklusi adalah pemetik teh yang memetik daun teh dengan cara manual dan $\mathrm{k}$ riteria eksklusi adalah pekerja yang pernah trauma atau terdapat riwayat operasi pada pergelangan tangan. Kegiatan lain yang melibatkan pergelangan tangan : bengkel, penjual rujak, juru ketik dan faktor intrinsik seperti jenis kelamin,umur, kehamilan dan riwayat penyakit diabetes.

Penentuan besar sampel ditentukan dengan rumus Slovin (1960), yaitu :

$$
\mathrm{n}=\frac{N}{1+N\left(e^{2}\right)}
$$

Keterangan :

$\mathrm{N}=$ jumlah populasi, sedangkan $\mathrm{n}=$ jumlah besar sampel, serta e2 $=$ batas toleransi kesalahan.

$$
\begin{aligned}
\mathrm{n} & =\frac{105}{1+105(0,05)^{2}} \\
\mathrm{n} & =83,168 \text { dibulatkan menjadi } 85
\end{aligned}
$$

Setelah dilakukan penentuan sampel sesuai karakteristik dan pemeriksaan tes tinnel dan phalen pada pekerja pemetik daun teh, langkah berikutnya adalah melakukan pengolahan dan analisis data. Analisis data pada penelitian ini menggunakan Uji Chi-square angka kejadian berdasarkan umur dan masa kerja dan Uji korelasi Pearson untuk melihat adakah korelasi antara masa kerja terhadap kejadian CTS pada pekerja perkebunan teh.

\section{Hasil Penelitian}

Penelitian ini dilakukan dengan tujuan untuk mengetahui hubungan masa dan lama kerja terhadap kejadian CTS pada pekerja perkebunan teh di Kebun Teh Wonosari, desa Toyomarto, Kecamatan Singosari, Kabupaten Malang yanh dilakukan kurang lebih 1bulan mulai bulan Juli 2016 sampai dengan Agustus 2016. Sampel pada penelitian ini adalah pemetik daun teh di Kebun Teh Wonosari, desa Toyomarto, Kecamatan Singosari, Kabupaten Malang yang memenuhi kriteria inklusi dan eksklusi dan didapatkan 85 orang.

Data umum yang didapatkan adalah 85 pekerja dengan karakteristik (tabel 3.1). Dari tabel 3.1 karakteristik responden angka kejadian CTS 56 (65,9\%), berdasarkan usia angka kejadian CTS meningkat setelah umur 40 tahun dan angka kejadian CTS tertinggi terjadi antara umur 50-59 tahun. Karakteristik responden berdasarkan masa kerja anka kejadian CTS meningkat setelah masa kerja 30 tahun tahun dan angka kejadian CTS tertinggi terjadi pada masa kerja 30-39 tahun.

\section{Tabel 3.1 Karakteristik usia responden, masa kerja dan kejadian CTS}

\begin{tabular}{ccc}
\hline Karakteristik Sampel & Normal & CTS \\
\hline Usia & & \\
$30-39$ & $2(2,4 \%)$ & $1(1,2 \%)$ \\
$40-49$ & $11(12,9 \%)$ & $14(16,5 \%)$ \\
$50-59$ & $11(12,9 \%)$ & $26(30,6 \%$ \\
$60-69$ & $4(4,7 \%)$ & $12(14,1 \%)$ \\
$70-79$ & $1(1,2 \%)$ & $3(3,5 \%)$ \\
& & \\
\hline
\end{tabular}

\begin{tabular}{ccc} 
Masa kerja (tahun) & \\
$10-19$ & $1(1,2 \%)$ & - \\
$20-29$ & $7(8,2 \%)$ & $5(5,9 \%)$ \\
$30-39$ & $10(11,8 \%)$ & $27(31,8 \%)$ \\
$40-49$ & $9(10,6 \%)$ & $12(17,6 \%)$ \\
$50-59$ & $2(2,4 \%)$ & $8(9,4 \%)$ \\
$60-69$ & - & $1(1,2 \%)$ \\
\hline & & \\
Kejadian CTS & $29(34,1)$ & $56(65,9 \%)$
\end{tabular}


Untuk mengetahui hubungan masa kerja dengan kejadian CTS dapat di lihat pada tabel 3.2

Tabel 3.2. Korelasi antara masa kerja dengan kejadian CTS

\begin{tabular}{llcc}
\hline & & Masa Kerja & CTS \\
\hline Masa Kerja & Pearson correlation & 1 & 0,263 \\
& Sig. 92-tailed) & & 0,015 \\
& N & 85 & 85 \\
CTS & Pearson correlation & 0,263 & \\
& Sig. 92-tailed) & 0,015 & 1 \\
& N & 85 & 85
\end{tabular}

Dari tabel korelasi antara masa kerja dengan kejadian CTS tabel 3,2 menunjukan mempunyai nilai korelasi yang positif $(0,263)$ yang artinya makin lama masa kerja maka angka kejadian CTS akan semakin besar dengan nilai signifikansi $0,015(<0,05)$

\section{Pembahasan}

Gangguan yang terjadi pada kesehatan seorang pekerja dapat disebabkan oleh berbagai faktor, baik yang berhubungan dengan pekerjaan maupun yang tidak berhubungan dengan pekerjaan. Salah satu bentuk pengaruh perilaku kerja terhadap terhadap kejadian CTS adalah pekerja sering menggunakan gerakan tangan saat bekerja dalam waktu yang lama dan berulang sehingga dapat menyebabkan gangguan pada jaringan sekitar terowongan pergelangan tangan yang dapat memicu terjadinya proses inflamasi sehingga menyebabkan saluran terowongan menjadi sempit dan menekan Nervus medianus dan menyebabkan penyakit CTS.

Masa kerja menunjukkan lamanya paparan di tempat kerja, semakin lama masa kerja maka akan semakin tinggi resiko terjadinya penyakit akibat kerja, salah satunya adalah CTS. Salah satu usaha industri yang berpotensi menimbulkan penyakit CTS adalah perkebunan teh. Pemetikan daun teh sendiri dapat dilakukan dengan dua cara, yaitu dengan menggunakan tangan secara manual (hand plucking) atau menggunakan bantuan mesin (mechanical plucking). Mahalnya harga untuk membeli mesin pemetik teh menyebabkan masyarakat lebih memilih memetik dengan cara manual, sehingga sangat berpotensi terjadi CTS yang akhirnya berimbas secara langsung terhadap berkurangnya produksi teh di tempat mereka bekerja.

Jika ditinjau dari faktor yang berhubungan dengan pekerjaan, aktivitas yang dapat mencetuskan CTS adalah paparan terhadap gerakan berulang dan cepat atau akibat kesalahan posisi yang terjadi dalam jangka waktu lama (Daryono et al, 2013).

Kejadian CTS akan semakin meningkat sebanding dengan meningkatnya usia dan lamanya masa kerja. Hal ini telah dibuktikan dari penelitian-penelitian sebelumnya yang menyatakan bahwa usia $>50$ meningkatkan resiko terjadinya CTS akibat penyusutan pada massa otot khususnya di bagian pergelangan tangan (Ronald, 2007). Penelitian yang dilakukan oleh Wieslander pada tahun 1989 yang menyimpulkan bahwa masa kerja $>20$ tahun mempunyai resiko lebih besar dibandingkan masa kerja $<20$ tahun.
Pada tabel 5.1. karakteristik responden berdasarkan usia angka kejadian CTS meningkat setelah umur 40 tahun dan angka kejadian CTS tertinggi terjadi antara umur 50-59 tahun $(30,6 \%)$ hal ini mendukung teori yang dikemukan oleh Ronal tahun 2007. Karakteristik responden berdasarkan masa kerja angka kejadian CTS meningkat setelah masa kerja 30 tahun tahun dan angka kejadian CTS tertinggi terjadi pada masa kerja 30-39 tahun (31,8\%). Hal ini juga mendukung penelitian yang dilakukan oleh Wieslander pada tahun 1989.

Masa kerja menunjukkan lamanya paparan di tempat kerja. Sehingga, semakin lama masa kerja maka akan semakin tinggi resiko terjadinya penyakit akibat kerja seperti CTS (Lukman, 2013). Salah satu kegiatan yang memiliki faktor risiko terkena kejadian CTS adalah saat melakukan gerakan untuk memetik daun teh. Pada pekerja pemetik daun teh banyak melakukan gerakan tangan berulang baik dengan postur pergelangan tangan fleksi atau ekstensi, deviasi ulnar dan radial ataupun supinasi dan pronasi. Sebagian besar pemetik daun teh melakukan gerakan tangan berulang dengan frekuensi tinggi dan cepat atau akibat kesalahan posisi ergonomis dalam jangka waktu lama yang akan meningkatkan risiko untuk terjadinya tendinitis. Kerusakan ini dapat menjadi penyebab terjadinya kompresi pada saraf (Daryono et al, 2013). Pada penelitian sebelumnnya juga dijelaskan oleh Osorio et al (1995) di pekerja supermarket, menyimpulkan bahwa masa kerja dan gerakan berulang mempunyai kecenderungan sebagai salah satu faktor resiko terjadinya CTS. Penelitian yang dilakukan Silvestrein et al (1987) juga menyimpulkan bahwa masa kerja dan gerakan berulang mempunyai hubungan dan resiko $5 x$ lebih tinggi daripada CTS yang diakibatkan oleh penggunaan kekuatan tangan. Kondisi ini didukung dari hasil penelitian ini yang dapat dilihat pada tabel korelasi antara masa kerja dengan kejadian CTS tabel 5,2 menunjukan bahwa nilai korelasi adalah positif $(0,263)$ yang artinya makin lama masa kerja maka angka kejadian CTS akan semakin besar dengan nilai signifikansi 0,015 $(<0,05)$.

Berdasarkan penelitian ini kami menyarankan untuk lebih mewaspadai pekerja-pekerja yang telah berumur 40 tahun karena Angka kejadian CTS meningkat setelah umur 40 tahun dan angka kejadian CTS tertinggi terjadi antara umur 50-59 tahun (30,6\%). Selain itu pekerja dengan masa kerja lebih dari 30 tahun juga sangat rentan untuk terjadinya CTS. 


\section{Kesimpulan dan Saran}

Berdasarkan hasil penelitian dan pembahasan di atas, maka dapat ditarik kesimpulan sebagai berikut:

1. Angka kejadian CTS pada pekerja pemetik daun teh adalah 56 ( 65,9\%)

2. Angka kejadian CTS meningkat setelah umur 40 tahun dan angka kejadian CTS tertinggi terjadi antara umur 50-59 tahun (30,6\%).

3. Anka kejadian CTS meningkat setelah masa kerja 30 tahun tahun dan angka kejadian CTS tertinggi terjadi pada masa kerja 30-39 tahun (31,8\%).

4. Semakin lama masa kerja maka angka kejadian CTS akan semakin besar

\section{Saran}

1. Bagi peneliti lain

a. Perlunya diteliti ulang dengan menggunakan metode penelitian yang lebih baik dan mengembangkan variabel dengan menganalisis seberapa besar pengaruh faktorfaktor lain yang dapat meningkatkan resiko CTS misalnya: riwayat DM dan obesitas dan lain-lain) sebagai upaya preventif untuk mengurangi angka kejadian CTS.

b. Dalam penelitian selanjutnya diharapkan agar memperbanyak sampel saat pengambilan data dan untuk faktor resiko CTS seperti DM diharapkan menggunakan screening seperti GDP dan GD2PP agar mendapat hasil pasti.

2. Bagi masyarakat dan pihak perusahaan

a. Sebagai masukan kepada masyarakat terutama para pekerja untuk lebih memperhatikan kondisi kesehatan, khususnya riwayat penyakit yang berhubungan dengan kejadian CTS, serta menerapkan edukasi untuk memperkecil resiko terjadinya penyakit akibat kerja, khususnya CTS seperti :

1) Gunakan bantuan mekanis atau mesin,

2) Sering dilakukannya rotasi jenis pekerjaan dengan gerakan berbeda.

3) Istirahat disela pekerjaan dan melakukan senam tangan saat istirahat.

4) Merendam air hangat setelah pulang bekerja

b. Diharapkan agar pihak industri melakukan pemeriksaan kesehatan rutin secara berkala terutama yang berkaitan dengan penyakit akibat kerja dan faktor resiko yang mempengaruhinya.

3. Bagi Petugas Kesehatan

Besarnya jumlah kejadian CTS pada pekerja pemetik daun teh dalam penelitian ini diharapkan dapat menjadi masukan bagi petugas kesehatan untuk memperhatikan kondisi kesehatan pekerja secara menyeluruh, terutama keluhan yang berhubungan dengan pekerjaan, sehingga keluhan dapat segera ditangani dengan baik sekaligus dapat meningkatkan produktifitas para pekerja dan mengurangi kecacatan.

\section{DAFTAR PUSTAKA}

United States Centers for Disease Control and Prevention Government Agency., 1997. Hand/Wrist Musculosceetal Disorder(Carpal Tunnel Syndrome, Wrist Tendinitis, and Hand Vibration Syndrome): Evidence for Work Relatedness, United States of America. pp 238-260

American Academy of Orthopaedic Surgeons, 2007. Clinical Practice Guidelines on The Diagnosis of Carpal Tunnel Syndrome, United State: American Academy of Orthopaedic Surgeons. pp 10-22

Anderson, V. P. et al., 1997. Musculoskeletal Disorders and Workplace Factors: A Critical Review of Epidemiologic Evidence for Work-Related Musculoskeletal Disorders of the Neck, Upper Extremity, and Low Back, U.S: U.S Department of Health and Human Service. pp7-15

American Academy of Orthopaedic Surgeons, 2012. Informed Patient - Carpal TunnelReleaseSurgery.http:/ /

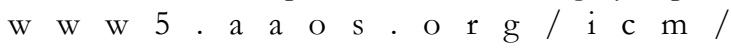
PrintModule.cfm? module $=\mathrm{icm} 002$ [Diakses 7 Mei 2014].

Anon., n.d. Tinel's Test. http://www.medscape.com/ [Diakses 21 Maret 2014].

Aroori S, Spance R.AJ 2008. Carpal Tunnel Syndrome. Ulster Med;77(1):6-17

Atroshi, I. et al., 1999. Prevalence of Carpal Tunnel Syndrome in General Population. JAMA, Volume 50, pp. 1355-1364.

Atya AM and Mansour T. 2011. Laser versus nerve and tendon gliding exercise intreating carpal tunnel syndrome. Life Science Journal. 8(2):413-418.

Bahrudin, M. 2013. Carpal Tunnel Syndrome dalam Buku Neurologi Klinis. UMM Press. Malang.

Baron, S., Miliron, M., Habes, D. \& Fidler, A., 1991. Hazard Evaluation and Technical Assistance Report: Shoprite Supermarkets, New Jersey: Department of Heath and Human Service. pp. 97-106

Barnardo J, 2004, Carpal Tunnel Syndrome, Arthitis Research Campaign (ARC).

Budiman M A, 2013, Sektor Pertanian dalam Konsep Pendapatan Nasional, Fakultas Pertanian Universitas Padjajaran, Bandung

Bugajska J, Jedrika A, Udol I. 2007. Metacarpal Syndrome in occupational medicine practice. International Journal of Occupational Safety and Ergonomics (JOSE). 13(1): 29-38.

Cochran, William G. 1991. Teknik Penarikan Sampel. UI, Jakarta, pp. 25

Daryono, Wibawa, A. \& Tianing, N. W., 2013. Intervensi Ultrasound dan Free Carpal Tunel Exercise Lebih Efektif Dibanding Ultrasound dan Gliding Exercise Terhadap Penurunan Nyeri pada Kasus Carpa Tunnel Syndrome, Bali: Fakultas Kedokteran Universitas Udayana. pp 2-6

Davis Larry E, Molly K. King,Jessica L. Schultz, 2005, Carpal tunnel syndrome in Fundamentals of Neurologic Disease, Demos Medical Publishing New York; 61-63 
Department of Insurance to the Workers Compensation Board. 2011. Carpal Tunnel Syndrome Medical Treatment Guideline. New York. pp. 3-18

Faiz, O. \& Moffat, D., 2004. At a Glance Anatomi. Jakarta: Erlangga. Jakarta, pp.63;67;83.

Fisher, B., Gorsche, R. \& Leake, P., 2004. Diagnosis, Cuasation, and Treatment of Carpal Tunnel Syndrome: An Evidance-Based Assesment.

Giersiepen K, Spallek M, 2011, Carpal Tunnel Syndrome as an Occupational Disease, viewed 2 June 2015, <http:/ /www.ncbi.nlm.nih.gov/pubmed/21547163>.

Grafton CH. 2009. Carpal Tunnel Syndrome.CME Resource;17(3):1-22.

Harahap, R., 2003. Praktis Carpal Tunnel. Cemin Dunia Kedokteran, Volume 141:51-53.

Ho C T, Lin J K, Shahidi F, 2009, Tea and Tea Products: Chemistry and Health-Promoting Properties, Boca Raton, United States of America: CRC Press.

International Labour Organization (ILO). 2013. The Prevention Occupational Diseases. ISSA. Switzerland. pp. $30-80$

Iriani, T., 2010. Hubungan Repetitive Motion dengan Keluhan Carpal Tunnel Syndrome pada Pekerja Menjahit di Bagian Konveksi PT Dan Liris Sukoharjo Surakarta, Solo: Keselamatan dan Kesehatan Kerja Fakultas Kedokteran UNS.

Kamath V, Stothard J, 2004, A Clinical Questionnaire for The Diagnosis of Carpal Tunnel Syndrome. Middlesbrough General Hospital: Department of Orthopaedic Surgery.

Kementrian Pertanian, 2014, Perkembangan Pasar Teh Indonesia di Pasar Domestik dan Pasar Internasional, viewed 30 April 2015, <http:// balittri.litbang.pertanian.go.id/index.php/berita/infoteknologi/207-perkembangan-pasar-teh-indonesia-dipasar-domestik-dan-pasar-internasional $>$.

Keputusan Presiden Republik Indonesia Nomor 22 Tahun 1993.Penyakit yang Timbul Karena Hubungan Kerja. 27 Februari 1993. Presiden Republik Indonesia. Jakarta.

Kurniawan, B., Siswi Jayanti, Yulianing Setyaningnsih. 2008. Faktor Risiko Kejadian Carpal Tunnel Syndrome (CTS) pada Wanita Pemetik Melati di Desa Karangcengis Purbalingga. Jurnal Promosi Kesehatan Indonesia 3(1): 2. pp. $5-8$

Merijanti, Lie T. 2005. Gerakan Repetitif Berulang Sebaga Faktor Resiko Terjadinya Sindrom Terowongan Karpal Pada Pekerja Wanita di Pabrik Pengolahan Makanan. Universa Medicina.

Moore, K. L., Dalley, A. F., Agur, A. M. \& Moore, M. E., 2013. Anatomi Berorientasi Klinis. 5 ed. Jakarta: Erlangga.

Morgenstern et al. 1999. A Cross-Sectional Study of Hand/ Wrist Symptoms in Female Grocery Checker. Am J Ind Med . 20 (2):209-218.

Nguyen, A., n.d. Carpal Tunnel syndrome. http:// www.lakeoswegoplasticsurgery. com/hand/ phalen_maneuver_s.png [Diakses 21 maret 2014].

Nursalam, 2008, Konsep dan Penerapan Metodologi Penelitian Ilmu Keperawatan. Jakarta: Salemba Medika

Osorio AM et al. 1991. Carpal Tunnel Syndrome. J Occup Med. 25(2): 229-245
Pemerintah Kabupaten Malang, 2014, Agro Kebun Teh Wonosari, viewed 30 Mei 2015, <http:// www.malangkab.go.id $>$.

Peraturan Menteri Tenaga kerja dan Transmigrasi No. Per.01/ MEN/1981. Kewajiban Melapor Penyakit Akibat Kerja. 4 April 1981. Menteri Tenaga Kerja Dan Transmigrasi. Jakarta.

Putz, R. \& Pabst, R., 2007. Atlas Anatomi Manusia Sobotta. 22 ed. Jakarta: Penerbit Buku Kedokteran EGC.

Ronald, P. E., 2006. Nyeri dan Kebas Pergelangan Tangan Akibat Pekerjaan.

Silverstein, BA. Fine, LJ. Armstrong, TJ.1987. Occupational factors and carpal tunnel syndrome. American Journal of Industrial Medicine, 11:343-358.

Snell, R.S., 2006. Anatomi Klinik. Edisi 6. Penerbit Buku Kedokteran EGC. Jakarta.

Tana L, 2003, Sindrom terowongan karpal pada pekerja : pencegahan dan pengobatannya. Universitas Trisakti. Jakarta. pp.73-82

Tarwaka, dkk. 2004. Ergonomi Untuk Keselamatan Kesehatan Kerja dan Produktivitas. Surakarta: UNIBA Press.

Weislander G, Norback D, Goethe CJ, Juhlin L. 1989. Carpal tunnel syndrome and exposure to vibration, repetitive wrist movements and heavy manual work: a case referent study. Br J Indust Med;46:43 \pm 7 .

Werner, R., Franzblau, A., Albers, J. \& Armstrong, T., 1996. Influence of Body Mass Index and Work Activity on the Prevalence of Median Neuropathy at The Wrist. Occupational Environment Medical, Volume 54, pp. 268-271.

World Health Organization. 2012. Occupational Health. http://www.who.int /occupational_health/en/ index.html. [Diakses 22 Februari 2013]

Wyss, J., Amrish Patel. 2013. Therapeutic Programs for Musculosceletal Disorders. Demos Medical. New Jersey.

Zens C. 1994. Cumulative Disorders of the Upper Extremity. In: Occupational Medicine. 3rd edn. New Yrk: Mosby Publishing:Chapter 5 